\title{
Immunologic, clinical, and radiologic status 14 months after cessation of natalizumab therapy
}

O. Stüve, $\mathrm{MD}, \mathrm{PhD}$

P.D. Cravens, PhD

E.M. Frohman, MD, $\mathrm{PhD}$

J.T. Phillips, MD, PhD

G.M. Remington, RN

G. von Geldern, MD

S. Cepok, PhD

M.P. Singh, PhD

J.W. Cohen Tervaert, $\mathrm{MD}, \mathrm{PhD}$

M. De Baets, MD, PhD

D. MacManus, MD

D.H. Miller, MD, PhD

E.W. Radü, MD

E.M. Cameron, BSc

N.L. Monson, PhD

S. Zhang, PhD

R. Kim, MD

B. Hemmer, MD*

Address correspondence and reprint requests to Dr. Olaf Stüve, Neurology Section, VA North Texas Health Care System, Medical Service, 4500 South Lancaster Rd., Dallas, TX 75216 olaf.stuve@utsouthwestern.edu

M.K. Racke, MD*

Supplemental data at www.neurology.org

Editorial, page 392

\section{ABSTRACT}

Objective: Natalizumab is a humanized recombinant monoclonal antibody against very late activation antigen-4 approved for the treatment of patients with multiple sclerosis (MS). A phase II study failed to demonstrate a difference between natalizumab treatment groups and the placebo group with regard to gadolinium enhancing lesions on MRI 3 months after discontinuation of therapy. The objective of this study was to assess clinical MS disease activity, surrogate disease markers on MRI, immunologic parameters in peripheral blood and CSF, as well as safety in patients with MS after discontinuation of natalizumab therapy.

Methods: This study is a longitudinal and serial cross-sectional assessment, in which 23 patients who were treated with natalizumab in the context of two phase III clinical trials were originally enrolled. A subgroup of patients was followed over 14 months. The annual relapse rate, neurologic disease progression assessed by the Expanded Disability Status Scale, disease surrogate markers on MRI, cellular and humoral immune markers in peripheral blood and CSF, and adverse events of the drug were monitored.

Results: With regard to clinical disease activity, neuroimaging, and immune responses, the majority of patients in our cohort were stable. Decreased lymphocyte cell numbers and altered cell ratios returned to normal 14 months after cessation of natalizumab. No infectious complications were observed.

Conclusion: This is the first long-term follow-up of patients who discontinued natalizumab. We did not observe a clinical, radiographic, or immunologic rebound phenomenon after discontinuation of natalizumab therapy. Neurology ${ }^{\circledR}$ 2009;72:396-401

\section{GLOSSARY}

EDSS = Expanded Disability Status Scale; FDA = Food and Drug Administration; $\mathbf{M S}=$ multiple sclerosis; OCB = oligoclonal band; PML = progressive multifocal leukoencephalopathy; VLA-4 = very late activation antigen 4 ; WBC = white blood cell.

Natalizumab is a humanized monoclonal antibody that binds to the $\alpha_{4}$ chain of the $\alpha_{4} \beta_{1}$ (very late activation antigen 4 [VLA-4]) and $\alpha_{4} \beta_{7}$ integrins. ${ }^{1}$ Based on the results of two phase III clinical trials, ${ }^{2,3}$ natalizumab was originally approved by the Food and Drug Administration (FDA) for the treatment of relapsing forms of multiple sclerosis (MS) on November 24, 2004. Subsequently, two patients with MS who had been enrolled in the SENTINEL phase III trial were diagnosed with progressive multifocal leukoencephalopathy (PML). ${ }^{4,5}$ Another patient with Crohn disease who had been treated with natalizumab in the context of clinical trials was later also diagnosed with PML. ${ }^{6}$

The purpose of this study was to assess MS disease activity with regard to relapse rate and accumulation of neurologic disability after discontinuation of natalizumab. Also, we quantified surrogate markers of MS disease activity by MRI, as well as immunologic parameters in peripheral blood and CSF.

e-Pub ahead of print on November 5, 2008, at www.neurology.org.

*These authors contributed equally to this work.

Authors' affiliations are listed at the end of the article.

Dr. Stüve was supported by a start-up grant from the Dallas VA Research Corporation, a New Investigator Award grant from VISN 17, Department of Veterans Affairs, a merit award from the Department of Veterans Affairs, research grants from National Multiple Sclerosis Society (NMSS; RG3427A8/T and RG2969B7/T), and a grant from the Viragh Foundation. Supported by grants (NS 37513 and NS 44250) from the NIH and NMSS grant RG 2969-B-7 to Dr. Racke. Drs. Hemmer and Cepok were supported by grants from the Deutsche Forschungsgemeinschaft (He 2386/ 4-2). Supported in part by the Adult AIDS Clinical Trials Group funded by the National Institute of Allergy and Infectious Diseases (AI 38858 and AI 27664). Dr. Monson was supported by a grant from the NIH (NS 40993).

Disclosure: The authors report no disclosures. While the AFFIRM monotherapy trial and the SENTINEL add-on trial with interferon beta-1a

(Avonex) were sponsored by Biogen-Idec Inc. and Elan Corp., the manufacturers of natalizumab, the work presented in this study was not. 


\begin{tabular}{|c|c|c|c|c|c|c|}
\hline Table & Patie & t characte & ristics & & & \\
\hline Patient & Gender & Diagnosis & EDSS* & Clinical trial & Relapse $^{+}$ & Medication ${ }^{*}$ \\
\hline 1 & Male & 1998 & 1.5 & N/AS & None & $\begin{array}{l}\text { Glatiramer acetate, } \\
\text { mycophenolate mofetil }\end{array}$ \\
\hline 2 & Female & 1990 & 4.5 & AFFIRM $\|$ & None & None \\
\hline 3 & Female & 2001 & 0 & AFFIRM & 2 & None \\
\hline 4 & Female & 1995 & 4.5 & AFFIRM & None & Interferon $\beta$-1a (Rebif) \\
\hline 5 & Female & 1992 & 0 & AFFIRM & None & Glatiramer acetate \\
\hline 6 & Female & 2002 & 4.0 & AFFIRM & None & None \\
\hline 7 & Female & 1995 & 3.5 & AFFIRM & None & None \\
\hline 8 & Female & 1999 & 1.5 & SENTINEL" & None & Interferon $\beta$-1a (Avonex) \\
\hline 9 & Female & 1999 & 3.5 & SENTINEL & None & $\begin{array}{l}\text { Interferon } \beta \text {-1a } \\
\text { (Avonex) (for } 8 \mathrm{mo} \text { ) }\end{array}$ \\
\hline 10 & Female & 1997 & 2.5 & SENTINEL & None & Interferon $\beta$-1a (Avonex) \\
\hline 11 & Female & 1994 & 6.0 & SENTINEL & None & Not known \\
\hline 12 & Female & 1989 & 2.5 & SENTINEL & None & Interferon $\beta$-1a (Avonex) \\
\hline 13 & Female & 1992 & 1.5 & SENTINEL & None & Interferon $\beta$-1a (Avonex) \\
\hline 14 & Female & 1999 & 1.5 & SENTINEL & None & Interferon $\beta$-1a (Avonex) \\
\hline 15 & Male & 1996 & 4.0 & SENTINEL & None & Interferon $\beta$-1a (Avonex) \\
\hline 16 & Female & 2000 & 1.5 & SENTINEL & None & Interferon $\beta$-1a (Avonex) \\
\hline 17 & Female & 2001 & 3.0 & SENTINEL & None & Interferon $\beta-1 \mathrm{a}$ (Avonex) \\
\hline 18 & Female & 1996 & 3.5 & SENTINEL & None & Interferon $\beta$-1a (Avonex) \\
\hline 19 & Female & 1999 & 2.5 & SENTINEL & None & Interferon $\beta$-1a (Avonex) \\
\hline 20 & Female & 1999 & 2.0 & SENTINEL & None & Interferon $\beta$-1a (Avonex) \\
\hline 21 & Female & 2001 & 2.0 & SENTINEL & 1 & Interferon $\beta$-1a (Avonex) \\
\hline 22 & Male & 2001 & 1.5 & SENTINEL & None & Interferon $\beta$-1a (Avonex) \\
\hline 23 & Female & 2001 & 3.5 & SENTINEL & None & $\begin{array}{l}\text { Interferon } \beta \text {-1a (Avonex), } \\
\text { mycophenolate mofetil }\end{array}$ \\
\hline
\end{tabular}

*Expanded Disability Status Scale (EDSS) assessed at time of enrollment in this study. 'The number of clinical relapses during the 14-month follow-up period is shown.

₹Shown are the pharmacotherapies patients were receiving after the discontinuation of natalizumab.

$\S N / A=$ Not applicable. Patient started natalizumab after initial approval by the Food and Drug Administration.

$\|$ AFFIRM $=$ Natalizumab safety and efficacy in relapsing remitting multiple sclerosis. "SENTINEL $=$ The safety and efficacy of natalizumab in combination with interferon $\beta$-1a in patients with relapsing-remitting multiple sclerosis.

METHODS Patients. Details on our patient cohort and control cohorts were previously reported. ${ }^{7,8}$ Written informed consent was obtained, and all study procedures were approved by the IRB.

Lymphocyte counts. Absolute cell numbers in peripheral blood were determined by a commercial clinical laboratory. CSF cells were counted as previously reported. ${ }^{7,8}$

Flow cytometry. PBMC were stained for flow cytometry and analyzed using standard methods. ${ }^{7,8}$

Biomarkers of humoral immunity. CSF and serum were examined for protein, albumin, and immunoglobulin $\mathrm{G}, \mathrm{A}$, and $\mathrm{M}$ levels by nephelometry (BN II; Behring, Marburg, Germany). The specific intrathecal production of IgG, IgA, and IgM was calculated according to the Reiber formula. ${ }^{9}$ CSF and serum were analyzed for oligoclonal bands (OCBs) by isoelectric focusing and IgG immunoblot (Titan Gel; Rolf Greiner Biochemica, Flacht, Germany).
Assessment of patient safety and clinical disease activity. The annual relapse rate was assessed in 21 patients for the 12-month period prior to enrollment into the AFFIRM and SENTINEL trials, for the trial period of the trials, and for the 14-month period after cessation of natalizumab (Tysabri). Neurologic disability assessed by the Expanded Disability Status Scale (EDSS) ${ }^{10}$ was recorded in 17 patients prior to enrollment into the AFFIRM and SENTINEL trial, at the time of cessation of natalizumab therapy, and 14 months after cessation of natalizumab. At these time points, study patients were seen and assessed for the occurrence of clinical relapses, infections, and any unexpected medical complications. In addition, at months 3, 9, and 12 after cessation of natalizumab therapy, patients were contacted by telephone.

Evaluation of MR images. Images from 16 patients were analyzed using a dual echo fast/turbo spin echo sequence giving scans with proton density, T1, and T2-weighted contrast while the patients were on natalizumab, and 14 months after cessation of therapy. All scans were performed at 1.5 Tesla.

Statistical analysis. Mann-Whitney $U$ paired test and Wilcoxon matched pair test were utilized to compare samples not independent of each other. GEE analysis was utilized to analyze recurrent event data. Prisms 4 (San Diego, CA) and SAS 9.1.3 (Cary, NC) software were used for data analyses. $p$ Values $<0.05$ were considered significant.

RESULTS Participants. The table summarizes the patient characteristics.

Peripheral blood leukocyte and lymphocyte counts. Total white blood cell (WBC) numbers in peripheral blood of natalizumab-treated patients with MS at study entry were within normal limits (figure 1A). A serial cross-sectional analysis of all study participants showed a nonsignificant decrease in leukocyte numbers at month 6 , and at month 14 after cessation of natalizumab. There was also a significant increase in the number of CD4 $+\mathrm{T}$ cells, CD8 $+\mathrm{T}$ cells, and $\mathrm{CD} 19+\mathrm{B}$ cells in peripheral blood 14 months after discontinuation of natalizumab therapy (figure 1, B-D), whereas the number of CD138+ plasma cells did not change (figure 1E). CD4:CD8 $\mathrm{T}$ cell ratios in peripheral blood remained within normal limits (figure 1F).

A longitudinal analysis showed a significant decrease of WBC between study entry and month 14 (figure 1G). It also confirmed the increase of $\mathrm{CD} 4+\mathrm{T}$ cells in peripheral blood 14 months after study entry, following an initial decrease at 6 months after cessation of natalizumab (figure $1 \mathrm{H})$. The number of CD8 $+\mathrm{T}$ cells did not change over the 14-month study period, but there was an initial significant decrease 6 months after cessation of natalizumab (figure 1I).

There was no correlation between the numbers of natalizumab doses received and cell numbers within peripheral blood and CSF (data not shown). There was also no difference in the number of cells between patients previously enrolled in the AFFIRM or SENTINEL trial (data not shown). 
Figure $1 \quad$ Analysis of leukocyte and lymphocyte cell numbers in peripheral blood (PB)
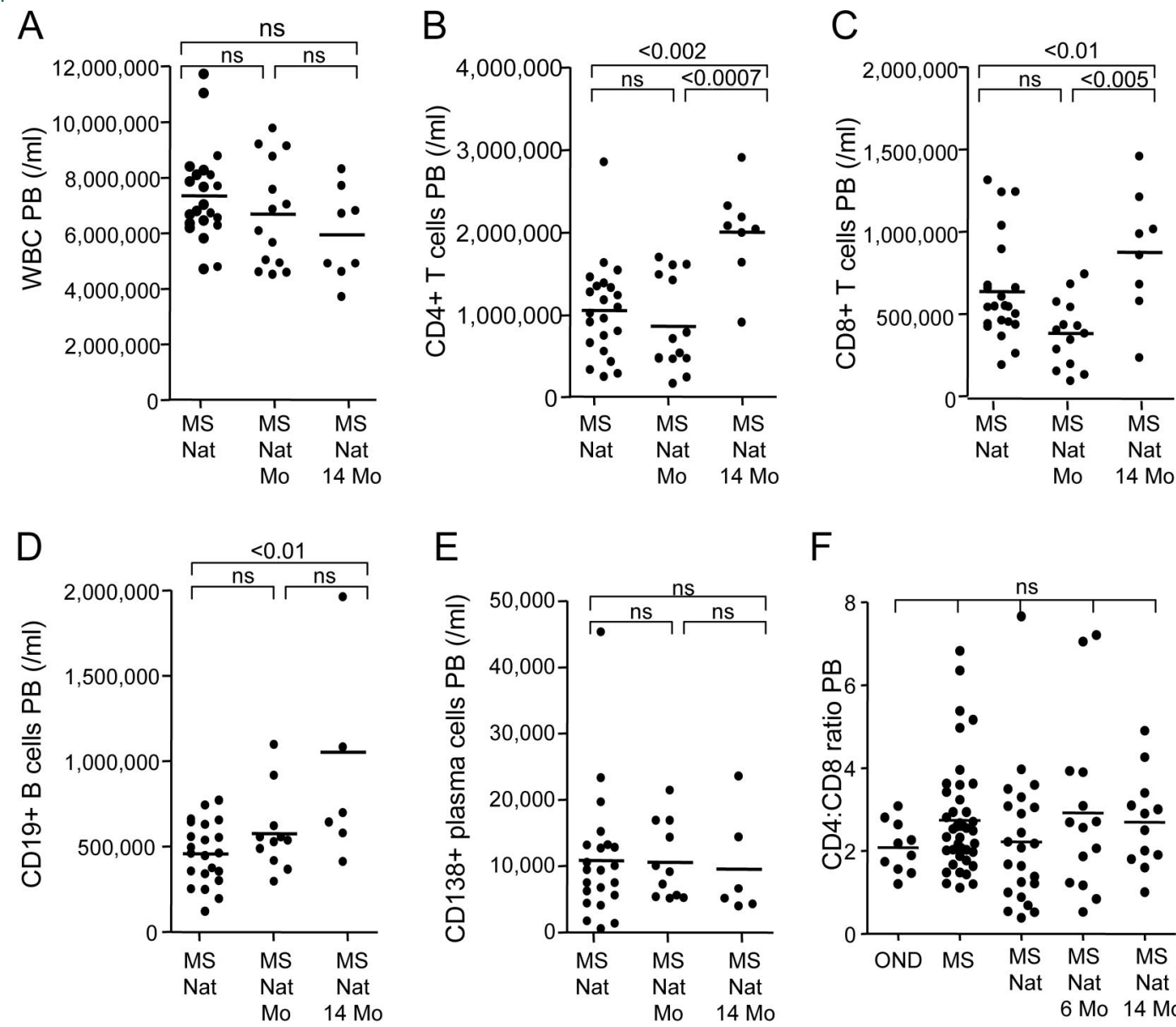

$\mathrm{F}$
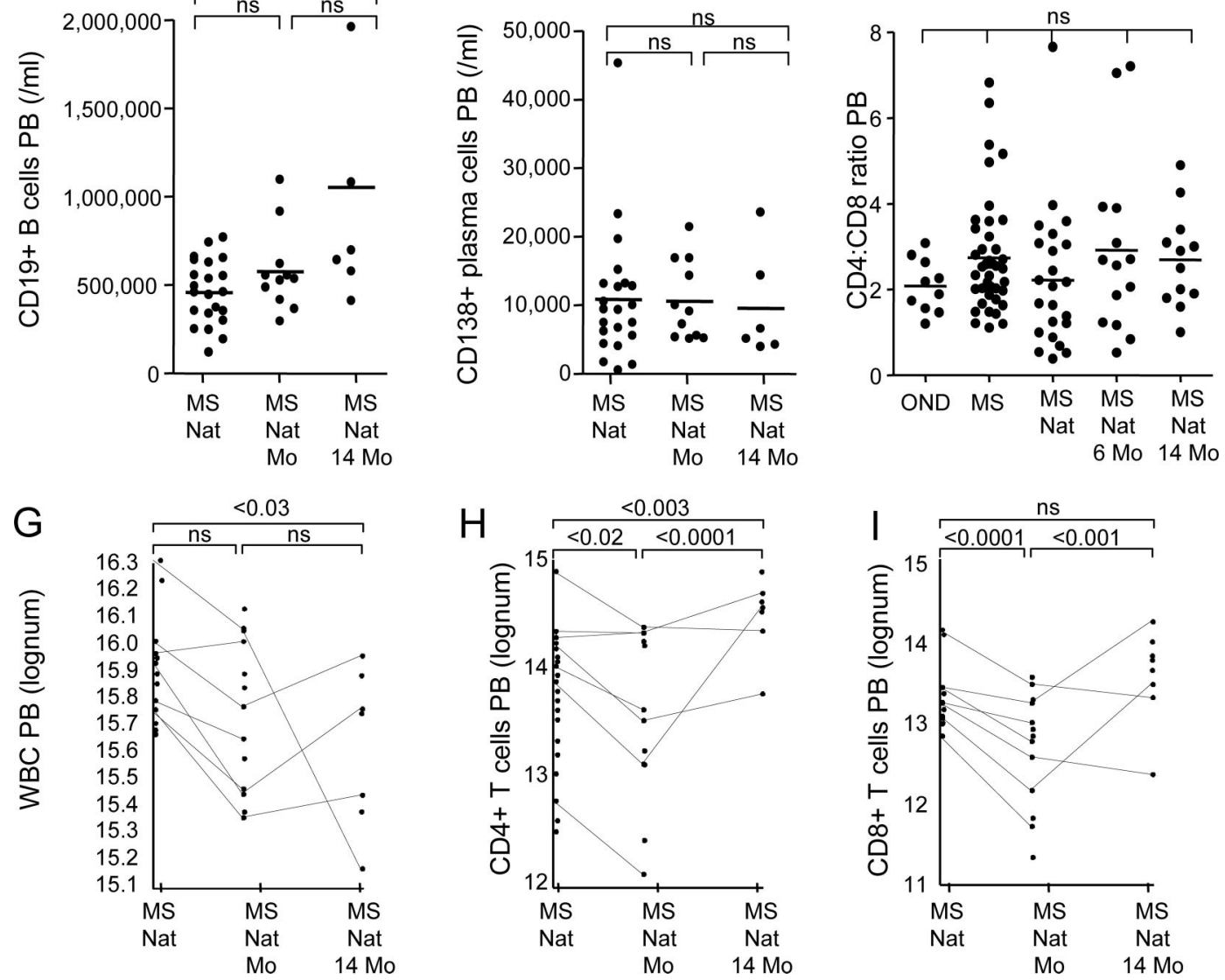

Serial cross-sectional analysis showed that the total numbers of white blood cells (WBC) in the PB of natalizumab-treated patients with multiple sclerosis (MS) at study entry (MS Nat) were within normal limits (A). There was a nonsignificant (ns) decrease in WBC numbers between the entry time point, 6 months (MS Nat 6 months), and 14 months (MS Nat 14 months) after cessation of natalizumab therapy (A). The number of CD4+ T cells (B), CD8+ T cells (C), and CD19+ B cells (D) significantly increased 14 months after discontinuation of natalizumab therapy, whereas the number of CD138+ plasma cells did not change (E). CD4:CD8 T cell ratios in the PB were normal at all three time points (F). Longitudinal analysis of leukocyte and lymphocyte cell numbers showed a significant decrease of WBC between study entry and month 14 (G). After an initial decrease at 6 months after cessation of natalizumab, there was an increase of CD4+ T cells in the PB 14 months after study entry $(H)$. The number of CD8+ T cells did not change over the 14-month study period, but there was an initial significant decrease 6 months after cessation of natalizumab (I).

CSF lymphocyte counts and phenotypes. A serial cross-sectional analysis of all study participants showed significantly fewer WBC, CD4 $+\mathrm{T}$ cells, CD8+ T cells, CD19+ B cells, and CD138+ plasma cells in CSF from natalizumab-treated patients with MS compared to patients with MS who had never received natalizumab therapy (figure e-1 on the Neurology ${ }^{\circledR}$ Web site at www.neurology.org), 
Figure 2 Humoral immune parameters in CSF
A PB
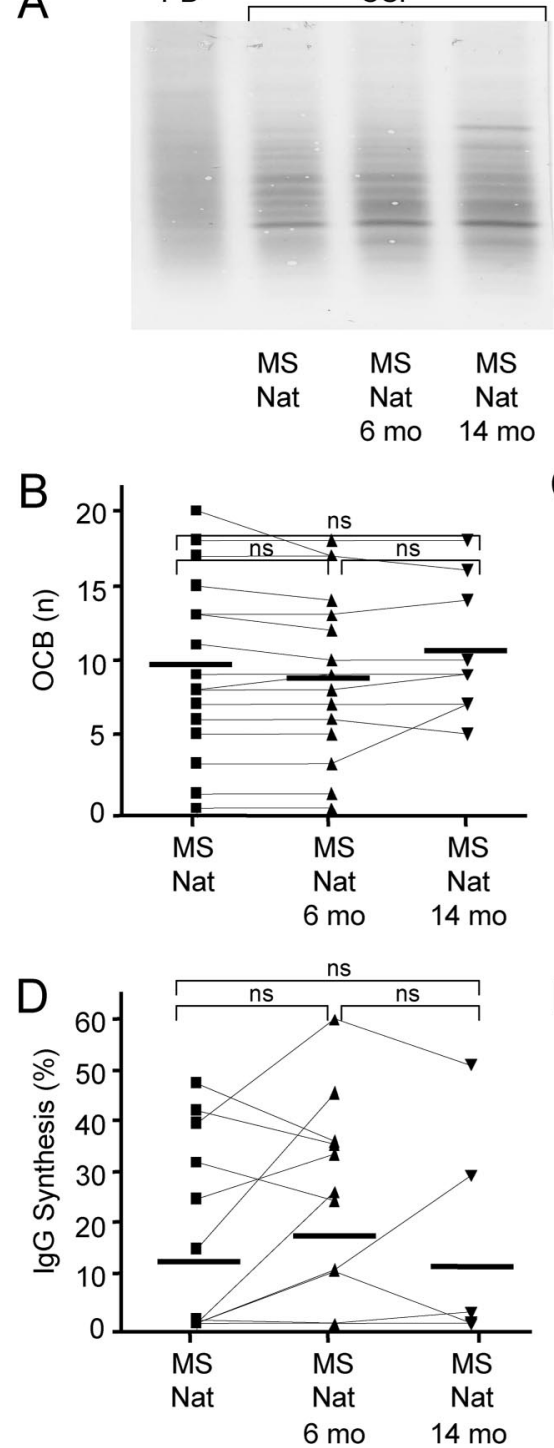

PB

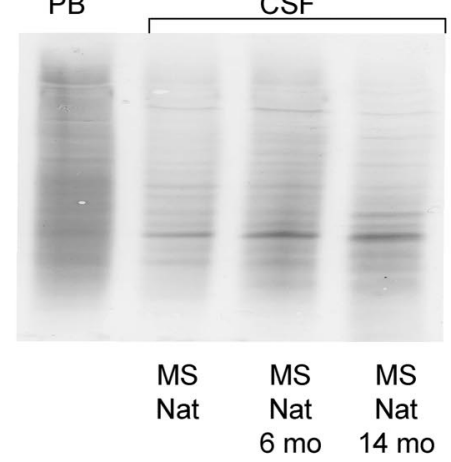

e-1). A longitudinal analysis of those patients showed very similar results (figure e-1).

Humoral immune parameters in the CSF. Two examples of OCBs are shown in figure $2 \mathrm{~A}$.

The number of OCBs, the amount of intrathecally synthesized IgG, and the CSF/serum albumin quotient did not differ between patients on natalizumab, 6 months, or 14 months after cessation of the drug (figure 2, B, D, and E). The total amount of intrathecal IgG increased significantly 6 months after cessation of natalizumab, and remained stable over the next 8 months (figure $2 \mathrm{C}$ ).

Patient safety. No serious adverse events were recorded during the 14-month time period after the cessation of natalizumab therapy.

Clinical disease activity. There was a significant decrease in the annual relapse rate in patients with MS on natalizumab during the AFFIRM and SENTINEL trials and during the 14-month period compared to the pretrial period (figure 3A). There was no significant difference with regard to neurologic disability as assessed by the EDSS scale among the three time points in this patient cohort (figure 3B).

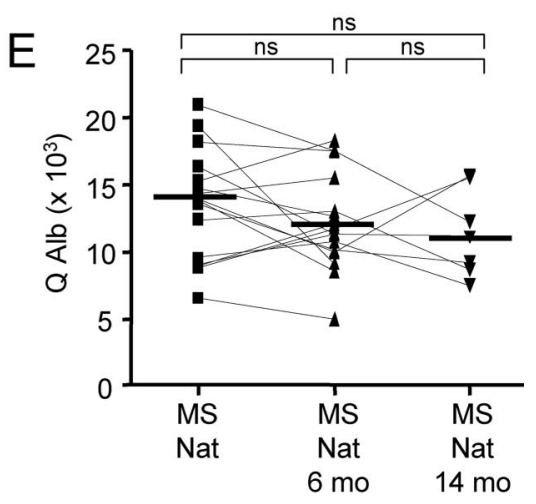

Oligoclonal bands (OCBs) were assessed in all patient samples. Two examples of the OCBs detection assay are shown (A). The number of OCBs (B), the amount of IgG synthesis (D), and the CSF/serum albumin quotient (E) did not differ between patients on natalizumab [MS (Nat)] and 6 months (MS Nat 6 months) or 14 months (MS Nat 14 months) after cessation of the drug. The total amount of intrathecal lgG increased significantly 6 months after cessation of natalizumab, and remained stable over the next 8 months (C).

as well as 6 months after cessation of natalizumab treatment (figure e-1). In contrast, 14 months after discontinuation of natalizumab, there was no significant difference in cell numbers between these cohorts (figure e-1). This was still true if the two patient outliers with the highest cell numbers at the 14-month time point were excluded from the analysis (data not shown). The CD4:CD8 T cell ratio in CSF, which was reversed in patients with MS who were treated with natalizumab, normalized 6 months after discontinuation of therapy, and remained normal after 14 months (figure
Disease activity on MRI. There was no significant difference with regard to gadolinium-enhancing $(\mathrm{Gd}+)$ lesions on T1-weighted images, and the total lesion volume on T2-weighted and FLAIR weighted images between patients on natalizumab and 14 months after cessation of treatment (figure 3, C-E).

DISCUSSION The pharmacodynamic duration of natalizumab is important for several reasons. In the context of a phase II clinical trial, it was shown that as early as 3 months after discontinuation of natalizumab there was no difference between the treatment group and the placebo groups with regard to $\mathrm{Gd}+$ lesions. ${ }^{11}$ Another group of investigators recently showed an increase in T2-weighted lesion activity on cerebral MR images in a cohort of 21 patients 15 months after cessation of natalizumab therapy. ${ }^{12}$ Thus, there is at least a theoretical concern that the discontinuation of natalizumab therapy may rapidly lead to a loss of its beneficial clinical effects, or even to a rebound phenomenon. Our own data do not support these concerns. Specifically, we did not observe a worsening of radiographic or immunologic disease activity after cessation of natalizumab therapy. In the majority of our patients, we also did not observe deterioration in their clinical status. It is important to point out that in contrast to the phase II trial mentioned above, ${ }^{11}$ the vast majority of patients in our cohort received other pharmacotherapies while involved in the SENTINEL combination trial, ${ }^{2}$ as well as after discontinuing natalizumab (table). The article by Vel- 
Figure $3 \quad$ Measurement of disease activity
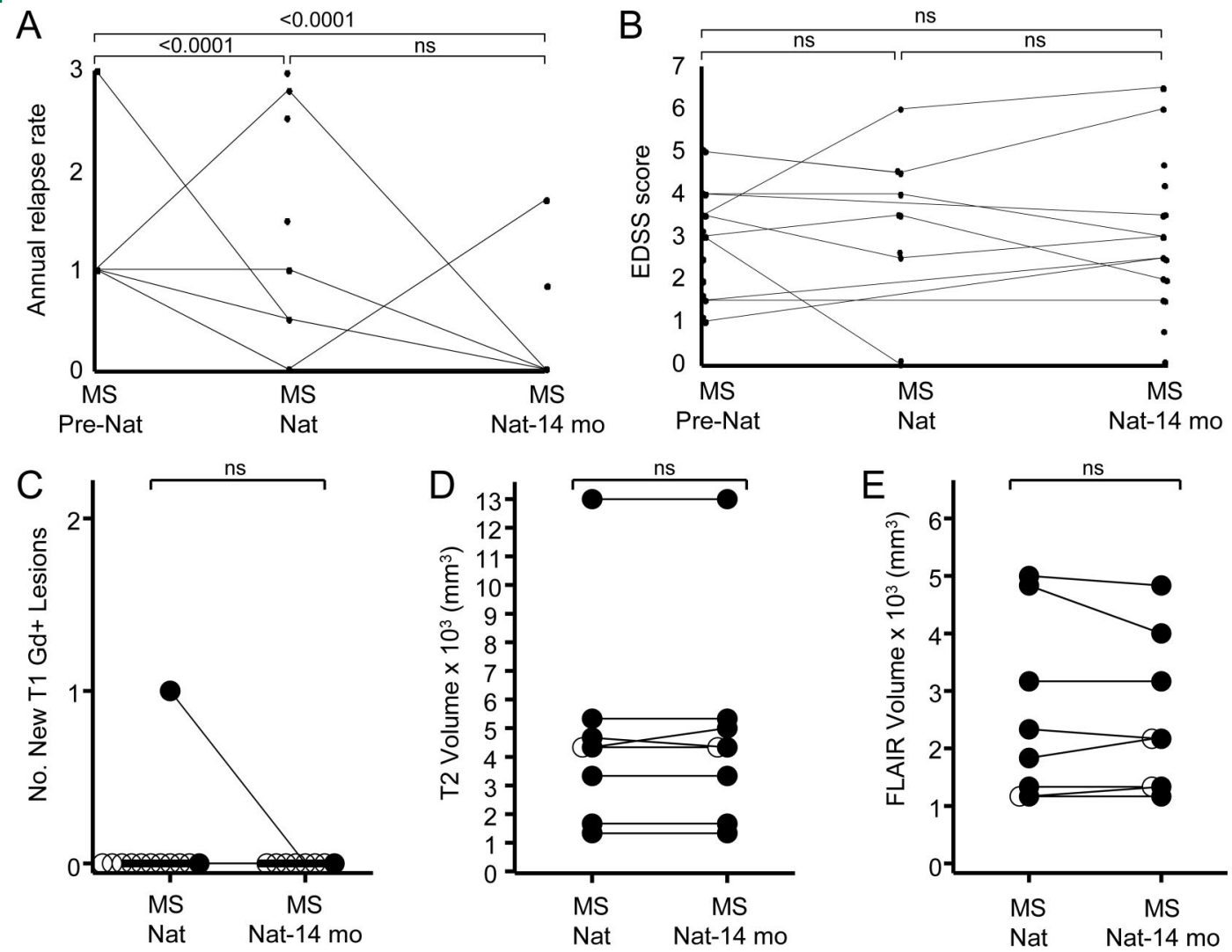

Longitudinal analysis of the annual relapse rate was assessed in 21 patients with multiple sclerosis (MS) for the 12-month period prior to enrollment into the AFFIRM and SENTINEL trials (MS pre Nat), for the trial period of the AFFIRM and SENTINEL trials (MS Nat), and for the 14-month period after cessation of natalizumab (MS Nat 14 months) (A). In addition, neurologic disability assessed by the Expanded Disability Status Scale (EDSS) was recorded in 17 patients prior to enrollment into the AFFIRM and SENTINEL trial (MS pre Nat), at the time of cessation of natalizumab therapy (MS Nat), and 14 months after cessation of natalizumab (MS Nat 14 months) (B). There was a significant decrease in the annual relapse rate in patients with MS on natalizumab during the AFFIRM and SENTINEL trials compared to the pretrial period (A). There was also a significant decrease in the annual relapse rate in the 14-month period after cessation of therapy compared to the pretrial period (A). In contrast, there was no significant difference in the annual relapse rate between patients on natalizumab during the AFFIRM and SENTINEL trials and during the 14-month period after cessation of natalizumab therapy (A). There was no significant difference with regard to neurologic disability as assessed by the EDSS scale among the three time points in this patient cohort (B). The number of new gadolinium-enhancing $(\mathrm{Gd}+)$ lesions on T1-weighted MRI (C), the total lesion volume on T2-weighted (D) and FLAIR-weighted images (E) was assessed while patients received natalizumab, and 14 months after discontinuation of therapy. There was no significant difference with regard to Gd+ lesions on T1weighted images $(C)$ and the total lesion volume on T2-weighted $(D)$ and FLAIR weighted images $(E)$.

linga et al. does not comment on the use of other disease-modifying therapies in their patients. ${ }^{12}$

We had shown earlier that patients with MS who are on natalizumab therapy as well as patients 6 months after discontinuation of natalizumab treatment have significantly decreased numbers of B cells and plasma cells in their CSF. It is intriguing that natalizumab therapy appears to have minimal effects on the total production of IgG in the CNS, and that there is no impact on the number of OCBs in the CSF. These observations may suggest that there are inflammatory lymphocytes in the CNS, including cells of the $\mathrm{B}$ cell lineage, that are present in the brain and spinal cord for long periods of time and independent of effects on further lymphocyte migration into the CNS.
The medical community is concerned with the risk of developing PML while on natalizumab therapy. ${ }^{13}$ Our 14-month data demonstrate that immune surveillance in the peripheral blood and CSF may be restored, even in patients who receive other immunomodulatory therapy. Our patients did not experience any symptoms associated with PML, other opportunistic infections, or any serious treatment-related complications.

\section{AUTHORS' AFFILIATIONS}

From the Neurology Section (O.S.), VA North Texas Health Care System, Medical Service, Dallas; Departments of Neurology (O.S., P.D.C., E.M.F., G.M.R., M.P.S., E.M.C., N.L.M.), Immunology (O.S., E.M.C., N.L.M.), Ophthalmology (E.M.F.), and Clinical Sciences (S.Z.), University of Texas Southwestern Medical Center at Dallas; Department of Neurology (O.S., G.v.G., S.C.), Heinrich Heine University Düsseldorf, 
Germany; Multiple Sclerosis Center at Texas Neurology (J.T.P.), Dallas; Departments of Clinical and Experimental Immunology (J.W.C.T.) and Neurology (M.D.B.), University Hospital Maastricht, The Netherlands; Department of Neuroinflammation (D.M., D.H.M.), Institute of Neurology, Queen Square, London, UK; Institute of Neuroradiology (E.W.R.), Department of Medical Radiology, University Hospital Basel, Switzerland; BiogenIdec (R.K.), Cambridge, MA; Department of Neurology (B.H.), Klinikum Rechts der Isar, Technische Universität München, Germany; and Department of Neurology (M.K.R.), The Ohio State University Medical Center, Columbus.

\section{AUTHOR CONTRIBUTIONS}

Olaf Stüve: Designed research, performed research, analyzed data, wrote the manuscript. Petra D. Cravens: Performed research, analyzed data, wrote the manuscript. Elliot M. Frohman: Designed research, performed research, wrote the manuscript. J. Theodore Phillips: Designed research, wrote the manuscript. Gina Remington: Performed research, analyzed data, wrote the manuscript. Gloria von Geldern: Performed research, analyzed data, wrote the manuscript. Sabine Cepok: Performed research, analyzed data, wrote the manuscript. Mahendra P. Singh: Performed research, analyzed data. J.W. Cohen Tervaert: Designed research, wrote the manuscript. Marc De Baets: Designed research, wrote the manuscript. David Mac Manus: Designed research, analyzed data. David H. Miller: Designed research, analyzed data. Ernst W. Radü: Designed research, analyzed data. Elizabeth M Cameron: Performed research, analyzed data. Nancy L. Monson: Designed research, performed research, analyzed data. Song Zhang: Performed research, analyzed data. Richard Kim: Analyzed data, wrote the manuscript. Bernhard Hemmer: Designed research, performed research, analyzed data, wrote the manuscript. Michael K. Racke: Designed research, performed research, analyzed data, wrote the manuscript.

\section{ACKNOWLEDGMENT}

The authors thank their patients for participation in this study; Jane Lee, Janey Phillips, Jill Fowler, Nancy Perna, and Subir Sinha for assistance in data acquisition; Lauren Tantalo and April Colina for technical assistance; and Dr. Steven Vernino for help with data analyses.

Received October 31, 2007. Accepted in final form June 9, 2008.

\section{REFERENCES}

1. Stuve O, Bennett JL. Pharmacological properties, toxicology and scientific rationale for the use of natalizumab (Tysabri) in inflammatory diseases. CNS Drug Rev 2007; 13:79-95.
2. Rudick RA, Stuart WH, Calabresi PA, et al. Natalizumab plus interferon beta-1a for relapsing multiple sclerosis. N Engl J Med 2006;354:911-923.

3. Polman $\mathrm{CH}$, O'Connor PW, Havrdova E, et al. A randomized, placebo-controlled trial of natalizumab for relapsing multiple sclerosis. N Engl J Med 2006;354:899910.

4. Kleinschmidt-Demasters BK, Tyler KL. Progressive multifocal leukoencephalopathy complicating treatment with natalizumab and interferon beta-1a for multiple sclerosis. N Engl J Med 2005;353:369-374.

5. Langer-Gould A, Atlas SW, Green AJ, Bollen AW, Pelletier D. Progressive multifocal leukoencephalopathy in a patient treated with natalizumab. N Engl J Med 2005;353: 375-381.

6. Van Assche G, Van Ranst M, Sciot R, et al. Progressive multifocal leukoencephalopathy after natalizumab therapy for Crohn's disease. N Engl J Med 2005;353:362-368.

7. Stuve O, Marra CM, Jerome KR, et al. Immune surveillance in multiple sclerosis patients treated with natalizumab. Ann Neurol 2006;59:743-747.

8. Stuve O, Marra CM, Bar-Or A, et al. Altered CD4+/ $\mathrm{CD} 8+\mathrm{T}$ cells ratios in cerebrospinal fluid of natalizumabtreated patients with multiple sclerosis. Arch Neurol 2006; 63:1383-1387.

9. Reiber H. External quality assessment in clinical neurochemistry: survey of analysis for cerebrospinal fluid (CSF) proteins based on CSF/serum quotients. Clin Chem 1995; 41:256-263.

10. Kurtzke JF. Rating neurologic impairment in multiple sclerosis: an expanded disability status scale (EDSS). Neurology 1983;33:1444-1452.

11. Miller DH, Khan OA, Sheremata WA, et al. A controlled trial of natalizumab for relapsing multiple sclerosis. $\mathrm{N}$ Engl J Med 2003;348:15-23.

12. Vellinga MM, Castelijns JA, Barkhof F, Uitdehaag BM, Polman $\mathrm{CH}$ Postwithdrawal rebound increase in T2 lesional activity in natalizumab-treated MS patients. Neurology 2008;70:1150-1151.

13. Stuve O, Marra CM, Cravens PD, et al. Potential risk of progressive multifocal leukoencephalopathy with natalizumab therapy: possible interventions. Arch Neurol 2007; 64:169-176.

\section{Learn. Earn. Network.}

\section{AAN Annual Meeting: An Excellent Value}

- Learn about the latest scientific advances in neurology

- Earn valuable CME credit and fulfill Maintenance of Certification requirements

- Network with your peers at exciting social events all week long

- Enjoy the convenience and value of all this and more—in just one meeting

Early registration and hotel deadline is March 20, 2009.

Register today at www.am.com/AM2009. 